\title{
Review of National-Level Personal Health Records in Advanced Countries
}

\author{
Jisan Lee ${ }^{1,2}$, Young-Taek Park ${ }^{3}$, Yu Rang Park ${ }^{4}$, Jae-Ho Lee ${ }^{5,6}$ \\ ${ }^{1}$ Department of Nursing Science, College of Life \& Health Sciences, Hoseo University, Asan, Korea \\ ${ }^{2}$ The Research Institute for Basic Sciences, Hoseo University, Asan, Korea \\ ${ }^{3}$ Research Institute for Health Insurance Review and Assessment, Health Insurance Review \& Assessment Service, Wonju, Korea \\ ${ }^{4}$ Department of Biomedical Systems Informatics, Yonsei University College of Medicine, Seoul, Korea \\ ${ }^{5}$ Department of Information Medicine, Asan Medical Center, University of Ulsan College of Medicine, Seoul, Korea \\ ${ }^{6}$ Department of Emergency Medicine, University of Ulsan Collage of Medicine, Seoul, Korea
}

Objectives: This review article examines international examples of personal health records (PHRs) in advanced countries and discusses the implications of these examples for the establishment and utilization of PHRs in South Korea. Methods: This article synthesized PHR case reports of Organization for Economic Co-operation and Development (OECD) member countries, the Global Digital Health Partnership website on PHRs, and patient portals of individual countries to review the status of PHR services. The concept and significance of PHRs were also discussed with respect to PHR utilization status in European Union and OECD countries. Results: A review of international PHR services showed that the countries shared common points regarding the establishment of Electronic Health Records and national health information infrastructure. In addition, the countries provided services centered on primary healthcare institutions and public hospitals. However, promoting more positive participation and increasing the PHR acceptance rate requires workflow integration, including Electronic Medical Records, the provision of incentives, and the preparation of a supportive legal framework. Conclusions: South Korea is also conducting a national-level PHR project. Since the scope of PHRs is extensive and a wide range of PHR services must be connected, an extensive trial-and-error process will be necessary. A long-term strategy should be prepared, and necessary resources should be secured to establish national-level PHRs.

Keywords: Personal Health Records, Electronic Health Records, Information Technology, Republic of Korea, Organisation for Economic Co-operation and Development

Submitted: January 19, 2021

Revised: March 14, 2021

Accepted: April 8, 2021

\section{Corresponding Author}

Jae-Ho Lee

Department of Information Medicine, Asan Medical Center, University of Ulsan College of Medicine, 88 Olympic-ro 43-gil, Songpa-gu, Seoul 05505, Korea. Tel: +82-2-3010-3350, E-mail: jaeholee@amc. seoul.kr (https://orcid.org/0000-0003-2619-1231)

This is an Open Access article distributed under the terms of the Creative Commons Attribution Non-Commercial License (http://creativecommons.org/licenses/by$\mathrm{nc} / 4.0 /$ ) which permits unrestricted non-commercial use, distribution, and reproduction in any medium, provided the original work is properly cited.

(C) 2021 The Korean Society of Medical Informatics

\section{Introduction}

The personal health record (PHR) is a "tool through which individuals can manage and share their own health information held by medical institutions and self-generated health data" [1]. The patient portal is an information technology application that is used in the field of healthcare to strengthen communication between patients and healthcare workers and facilitate participation by patients; it is considered to be a type of PHR [2]. PHRs are a different concept from Electronic Medical Records (EMRs) and Electronic Health Records (EHRs). EMRs and EHRs store medical or health 
records in a digital format and are used by healthcare providers to improve the quality of care [3]. EMRs are generally considered an internal organizational system, whereas EHRs are defined as an inter-organizational system and are used for the management of medical and health data at the national level. The EHR certification standards of the US Office of the National Coordinator for Health Information Technology (ONC) include the patient portal service. The websites or mobile applications of medical institutions are used to provide services, such as scheduling office visits, reporting diagnoses and test results, providing prescription information, requesting prescription refills, and exchanging emails with doctors [4]. Epic, a company with more than 70\% of the EMR market share in the United States, offers a PHR application (named MyChart) that patients can use to access their own medical information and manage the patient-generated health data (PGHD), including blood pressure data.

However, even with technological advances and the increased adoption of advanced EMRs, the use of PHRs has remained low in many areas. Unlike financial services, where mobile technology has made disruptive innovations, mobile technology has remained relatively silent in the healthcare area. There seem to be both hype and skepticism regarding its effectiveness and efficiency in medicine. In order to determine a nation's strategy for mobile health technology, it would be helpful to investigate what has been accomplished elsewhere and how systems have been designed in other countries.

PHRs have been established and used not only in the United States, but also in other Organization for Economic Co-operation and Development (OECD) member countries, such as Australia and member countries of the European Union (EU). South Korea introduced its EHR system earlier than other countries, and the rate of adoption was relatively high [5], but the introduction and propagation of PHRs have been very significantly delayed. The present review article examines overseas cases of PHR in advanced countries and discusses the implications of those examples for the establishment and utilization of PHRs in South Korea.

\section{Methods}

A literature survey was conducted to summarize similar concepts related to PHRs. The literature included PHR case reports of OECD member countries published since 2012, the Global Digital Health Partnership (GDHP) website on PHRs, and patient portals of individual countries to review the status of PHR services [6]. The aim of this study was to review national-level PHR cases in advanced countries and to discuss the implications of those cases for the establishment of national-level PHRs in Korea, which is why we selected the OECD report and GDHP website for review in this study. The PHR services reviewed in this article are limited to those provided at the national or state government level, and the features of the services such as the operating institution, development time and purpose, users' characteristics, and acceptance rate are described. The common features of PHR services are summarized, highlighting the implications for national-level PHR services in South Korea.

\section{Results}

\section{Concept and Significance of PHRs}

In contrast to EMR and EHR, the term PHR is used in a broad sense. Concepts similar to PHRs include patient portals, personally controlled Electronic Health Records (PCEHRs), and patient-accessible Electronic Health Records (PAEHRs) (Table 1). These are all different types of PHRs

Table 1. Concepts related to PHR and their descriptions

\begin{tabular}{lc}
\hline \multicolumn{1}{c}{ Concept } & Description \\
\hline Personal health record (PHR) & $\begin{array}{c}\text { An individual's life-long health record viewed from an integrative and comprehensive view- } \\
\text { point, including personal healthcare information provided by various healthcare institutions } \\
\text { and self-recorded health records. }\end{array}$ \\
$\begin{array}{ll}\text { A type of information technology and PHR used in the field of healthcare to strengthen com- } \\
\text { munication between patients and healthcare workers and promote participation by patients. } \\
\text { Personally controlled Electronic }\end{array}$ & $\begin{array}{c}\text { The previous name of the Australian "My Health Record," highlighting personal control of } \\
\text { the electronic health information summary of one's medical history. }\end{array}$ \\
Patient-accessible Electronic & A service that allows patients to freely access their own healthcare information online in Elec- \\
Health Record (PAEHR) & tronic Health Records or other healthcare information systems. PAEHR is concerned with \\
& patients' access to their Electronic Health Records. \\
\hline
\end{tabular}


that are specialized for different purposes. The common features are that these systems contain health information of individual patients and authorize their access to their own health information [7].

\section{Systemic Evaluations of PHRs}

1) $\mathrm{EU}$

To investigate the status of eHealth application by acute care hospitals between 2012 and 2013, a survey was conducted with the chief information officers of acute care hospitals in EU member countries and other European countries [8]. The survey on patients' online access to personal data, conducted with representatives from 1,753 hospitals, showed that the status was better than before (95\%), but $90 \%$ of the hospitals did not provide eHealth services.

In 2018, a survey was conducted among $27 \mathrm{EU}$ member countries to investigate the status of eHealth application by general practitioners [9]. The results of the survey on the PHR functions of the information system and the actual utilization of the functions showed that general practitioners were able to use less than $50 \%$ of the functions. Although the results showed an improvement compared to a similar survey conducted in 2013, the use of PHR functions was highly limited. Regarding the routinely used functions, a significant increase was found in the use of patient appointment requests (24\% in 2018 and 13\% in 2013) and prescription refill requests (22\% in 2018 and $13 \%$ in 2013), but the usage rate was less than $25 \%$ for both functions.

\section{2) OECD}

The OECD conducted a survey on the status of healthcare information technology application in 38 member countries between 2012 and 2015 and presented the status of PHRs and patient portfolios of the individual countries [10]. The results showed that patients in more than half of the subject countries were able to access their own EHRs, and those in 13 countries were able to interact with healthcare workers based on their own EHRs [10]. Increasingly many countries provide patients with a tool to access their own EHRs with functions for entering information on their disease conditions and information related to results, experiences, and clinical events. After the survey, significant progress was made in some countries to establish patient portals and PHRs. Table 2 shows the patients' portals and PHRs in selected subject countries.
3) Status of national-level application of patient portals and PHRs

(1) Australia, My Health Record: Australia started a PHR service in 2012 in the form of the PCEHR, by selecting optin registration procedures for individuals who wanted to participate. Currently, the model has been shifted to an optout model that allows those who do not want to be registered to withdraw themselves.

The My Health Record (MyHR) consists of personal healthcare records, Medicare records, and other data. Through MyHR, individuals can access their own health information and control access authorization by determining who can view their information. The information contained in MyHR is connected to hospitals, primary physicians, pharmacies, specialists' offices, and specialists in laboratory medicine and diagnostic radiology. This information can be shared between individuals and healthcare providers, depending on the personal settings.

MyHR provides services only through its website. To use the service in a mobile application, a third-party application must be installed depending on the purposes, and the application provides only the "view" function [11].

The number of records rapidly increased from 5,890,000 in July 2018 to $22,810,000$ in July 2020 [12]. The total number of documents is over 2.1 billion, and the number of clinical documents is over 80 million. Approximately $93 \%$ of primary physicians are registered, and $83 \%$ use the service. In addition, $95 \%$ of public hospitals are registered, and $91 \%$ use the service.

(2) United Kingdom, The NHS App: The significance of the NHS App is that it is a mobile PHR app service that the government provides to citizens to access healthcare services. The service began on December 31,2018, and the app had been installed more than 200,000 times as of January 2020. The functions of the app, which is available for both iOS and Android smartphones, include patient symptom input, outpatient appointments, prescription refill request, and medical record access, and the app allows users to register their organ donation and study participation status [13] (Figure 1). Future plans include providing additional functions for the online classification of patients and off-hour and emergency center contacts, enabling chronic patients to view summary care records through the app by 2020 , and gathering more patients participating in studies, with a goal of 1 million registrations by 2023/2024 [14].

To add new functions to the NHS App, the NHS has provided the NHS App library and opened the possibility of interlocking and integrating with apps produced by external 
Table 2. Names of national-level PHR and special features

\begin{tabular}{|c|c|c|c|}
\hline Country & Patient portal/PHR & Special features & Website/App store link \\
\hline Austria & $\begin{array}{l}\text { ELGA Patient's } \\
\text { portal }\end{array}$ & $\begin{array}{l}\text { National EHR (2015), discharge letters, lab and } \\
\text { radiology findings, medication information }\end{array}$ & https://www.gesundheit.gv.at \\
\hline Australia & $\begin{array}{l}\text { My Health } \\
\text { Record }\end{array}$ & $\begin{array}{l}\text { PCEHR, third-party mobile apps, website- } \\
\text { only access, organ donor information }\end{array}$ & https://www.myhealthrecord.gov.au/ \\
\hline Canada & MyHealthNS & $\begin{array}{l}\text { State government service, mobile app, service } \\
\text { terminated due to payment issues }\end{array}$ & $\begin{array}{l}\text { https://www.myhealthns.ca (service termi- } \\
\text { nated on March 31, 2020) }\end{array}$ \\
\hline Denmark & sundhed.dk & $\begin{array}{l}\text { Patient-reported outcome measures (PROM), } \\
\text { health declaration forms }\end{array}$ & https://www.sundhed.dk \\
\hline Estonia & e-Patient portal & $\begin{array}{l}\text { Health certification request, default parent's } \\
\text { access to records of patients under age } 18\end{array}$ & https://www.digilugu.ee/ \\
\hline Finland & My Kanta & $\begin{array}{l}\text { Nursing notes, maternity care data, } \\
\text { community care notes }\end{array}$ & https://www.kanta.fi/ \\
\hline Luxemburg & $\begin{array}{l}\text { Dossier de } \\
\text { soins partagé }\end{array}$ & DSP (shared care record) & https://www.esante.lu/portal/ \\
\hline Norway & Helsenorge & Health declaration forms & https://www.helsenorge.no/ \\
\hline Portugal & SNS Portal & $\begin{array}{l}\text { Digital mobile key, patient-generated health } \\
\text { data, mobile app }\end{array}$ & https://servicos.min-saude.pt/ \\
\hline Sweden & Journalen & $\begin{array}{l}\text { Integration with different electronic record } \\
\text { systems }\end{array}$ & https://www.1177.se/ \\
\hline $\begin{array}{l}\text { United King- } \\
\text { dom (England } \\
\text { and Wales) }\end{array}$ & NHS App & $\begin{array}{l}\text { Clinical trials, mobile app, organ donor } \\
\text { information }\end{array}$ & $\begin{array}{l}\text { iOS: https://apps.apple.com/gb/app/nhs-app/ } \\
\text { id1388411277\#?platform=iphone } \\
\text { Android: https://play.google.com/store/apps/ } \\
\text { details?id=com.nhs.online.nhsonline\&hl=en }\end{array}$ \\
\hline
\end{tabular}
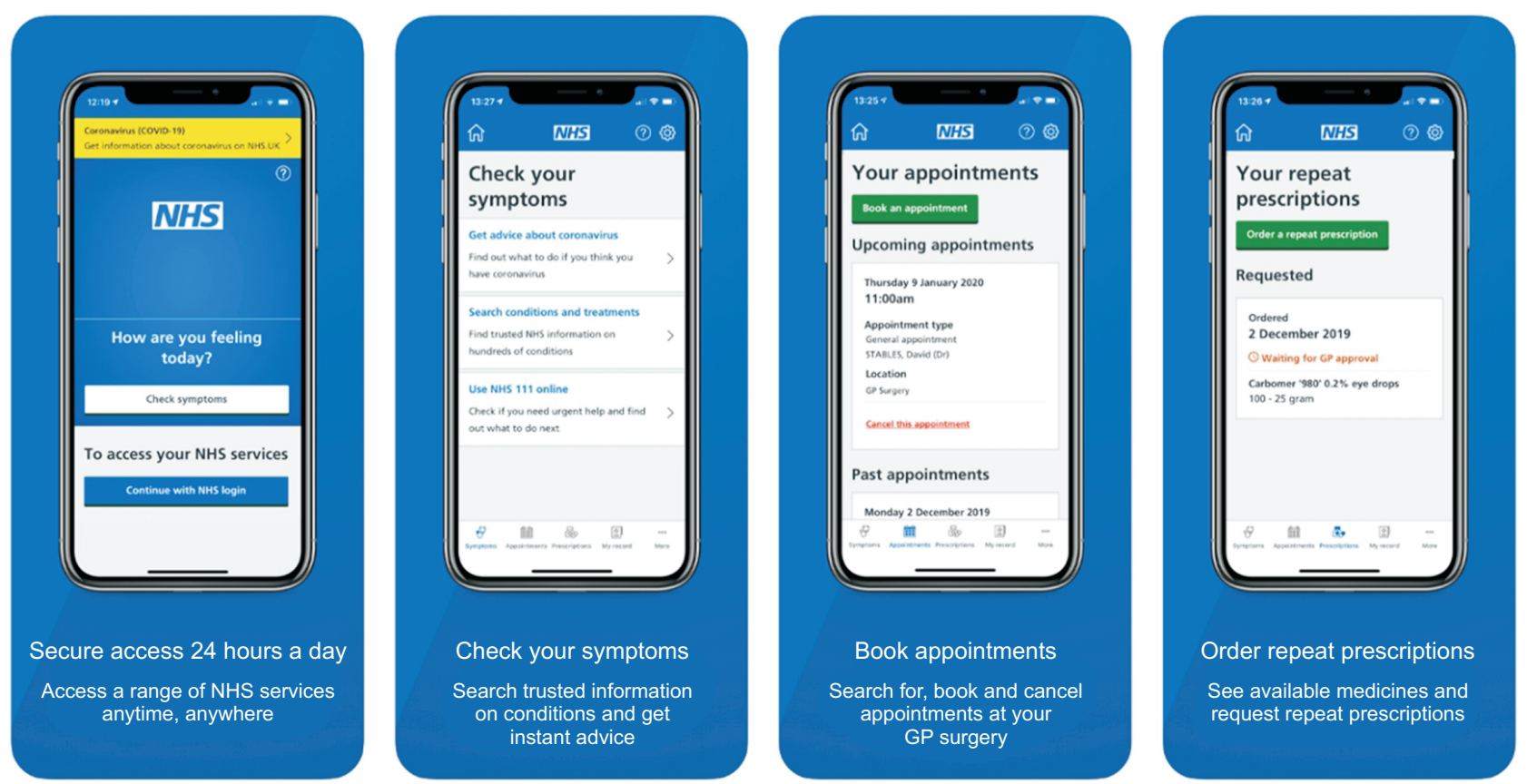

Figure 1. Screenshots of the NHS App of the United Kingdom (England). These screenshots shown in the Apple App Store explain that patients can input their symptoms, make outpatient appointments, and renew prescriptions (https://apps.apple.com/gb/app/ nhs-app/id1388411277\#?platform=iphone). 
medical information providers. In addition, the NHS supports fast healthcare interoperability resources (FHIR)-based application program interfaces (APIs) to secure interoperability for healthcare and medical welfare information and technology services by preparing a standard framework for medical information technology [15].

(3) Canada, MyHealthNS: The Nova Scotia state government provided residents with the MyHealthNS patient portal in July 2016. The patient portal enables patients and doctors to share information, including routine test results. When patients generate safe online health records (blood pressure measurements, vaccination information, allergic reactions, and administered medicines), they can download and save test results and expert reports. A pilot project was first conducted for 3 years with more than 30 doctors of family medicine and more than 6,000 patients; both the patients and doctors had positive participation in the project. About $98 \%$ of the patients wanted to continue receiving their results online, and $100 \%$ of the doctors shared the results online. The patients were able to access their own health information through smartphones, and the doctors improved their capability to care for patients by using the tool.

However, the service was terminated on March 31, 2020, because the issue of the PHR service payment model, raised in 2017, was not resolved [16]. When a patient used a telephone or PHR without visiting a doctor, the doctor was not paid at all. The income of some doctors decreased by $18 \%$, and their unpaid work time increased [17].

(4) Estonia, e-Patient Portal: In Estonia, all citizens who are health insurance policyholders can access their health data through a web-based patient portal. The e-Patient Portal (e$\mathrm{PP})$ provides access to the national health database by incorporating data from various healthcare providers of the EHR. Users can both access the data stored in the EHR and create summary documents (e.g., case summary and dental treatment chart), set alarms, make outpatient appointments, and notify all medical institutions simultaneously about changes in their contact details through the e-PP [18].

For data security, the system employs digital certification, digital signature, encryption, and distributed data storage technology, and all activity records are supported by blockchain technologies. As of 2018, approximately 480,000 users, accounting for $37 \%$ of the entire Estonian population, were active users.

(5) Sweden, Journalen: Sweden provides Journalen, a webbased patient portal PAEHR service [19] that enables users to access EHR information through a national health information exchange (HIE) platform. Patients have a single ac- cess point to all EHR information, regardless of the type of EHR system [20]. Sweden provides all patients with universal access to medical records, as all hospitals, primary clinics, and psychiatric facilities already use the EHR [21].

To introduce the system, Sweden invested resources for more than 20 years by legislating new laws and conducting clinical studies. In 2012, Sweden began a clinical study with 300,000 patients to allow them to access their EHRs. As of August 2019, more than 3 million users (more than 30\% of the population) had accessed their online records, and more than 2 million logins occurred each month [22].

\section{Discussion}

\section{Characteristics of Overseas National-Level PHRs}

1) A national-level EHR system and HIE platform is required The previous section reviewed the national-level PHR systems established in Australia, the United Kingdom, Estonia, and Sweden, and a state government-level PHR in Canada. In many countries, such as Austria, Latvia, Luxemburg, France, Finland, and New Zealand, patients are able to access their own EHRs and restrict access. There is one common feature among the PHRs of these countries-the EHR system was established at the national level or a national healthcare information infrastructure was simultaneously established.

2) PHR service is oriented towards primary healthcare institutions and public hospitals

The PHR services described above emphasize application to and participation in primary healthcare institutions, because public healthcare services make up a large proportion of health services in the abovementioned countries. In countries where private hospitals have a large share, such as South Korea, little is known about the manner and extent to which private hospitals participate in such services. It seems that detailed and complicated EMR information from tertiary healthcare institutions or university hospitals is not provided to PHRs. At present, the PHR service is provided mainly at participating public healthcare institutions supported by the government, so that the patients can access their own EHRs and interact with those records at primary healthcare institutions.

\section{3) Workflow integration is seriously considered}

An obstacle to PHR operations, commonly found in countries such as Australia, Canada, Estonia, and Austria, is the burden of operating the EMR system. Attempts to connect EMR systems to national EHRs have shown very low us- 
ability and are not integrated with the workflow, increasing the workload of healthcare workers and the burden of system management. In the OECD and GDHP reports, many experts mentioned improvements in the usability of EMRbased solutions, the integration of EMRs with the workflow, the protection of private health information, and the securing of data stability and accuracy as critical requirements of a PHR service.

\section{4) Healthcare workers' participation is critical}

Interaction with patients through PHRs and patient portals requires the participation of healthcare workers, who need to put in additional hours to respond to requests for online appointments and prescription refills and to review and correct the records. However, healthcare workers' lack of time is an obstacle to PHR participation. Many countries have introduced payment models and incentives, which have not been commonly identified as critical factors in healthcare workers' decision to participate [4].

Patients who used PHRs showed a better understanding of their treatment plans, better treatment control, increased drug compliance, improved communication with and trust in doctors, and improved safety [22]. Since healthcare workers are interested in patient outcomes, the positive results obtained from the use of the service may facilitate their participation.

\section{5) Patients' acceptance rate of PHRs varies substantially}

The PHR acceptance rate has been found to vary across countries. In Finland, 53\% of the subject population had accessed the patient portal by the end of 2017 [23]. In Sweden, more than 3 million users had accessed online records as of 2019. However, the number of downloads of the NHS App was only approximately 200,000 in the United Kingdom as of early 2020. The ratio of the population who used the patient portal at least once a month was less than $1 \%$ in Estonia and Australia, and less than 5\% in Denmark [24]. One of the reasons for the low acceptance rate is that EHRs lack interoperability. Patients must use different systems to access the data, which makes them feel isolated and frustrated. The connection between complicated private systems and wearable data is intricately associated with issues of data standardization and security. Northern European countries integrated national-level records accessible by patients with data from other electronic record systems in order to increase accessibility [22]. Another factor contributing to the low acceptance rate is insufficient support within the legal system for allowing patients to access their own health data online or the lack of effort for effective implementation of the system. In some countries, prepared legal regulations are not observed, or sanctions or incentives are not implemented to promote compliance with legal regulations.

\section{Implications for PHR Establishment and Application in South Korea}

South Korea has a plan to conduct a national-level PHR project (My HealthWay) for a short period of 3 years and with a relatively small budget. The initial approach may be focused on limited information and essential functions, because the scope of personal medical information is huge and a wide range of PHR services should be interlinked. An extensive trial-and-error process and a great deal of time will be invested in negotiating with stakeholders, including private medical institutions, and establishing PHRs for citizens. A long-term strategy and the necessary resources such as data standards, data integrity, and related regulations on PHRs should be prepared to establish the national-level PHR [7].

1) National system for health information exchange

One common feature of the international cases discussed herein is that the patient portal, PAEHR, and PCEHR systems were established based on a national-level EHR, EHR repository, or HIE system or infrastructure. At present, South Korea does not have a national-level EHR system. Citizens' opinions on EHRs have previously been found to be negative. In this situation, the provision of the My HealthWay service requires the development of a method of standardizing healthcare information from various medical institutions and providing it to patients. Currently, the available alternative is the national HIE system, which is necessary for the application of the PHR, the implementation of the HIE project between medical institutions, and the establishment of the EMR certification system. South Korea has already applied various standards to promote the HIE project and has used the Care Record Summary (CRS) for this purpose. However, to provide a PHR service, the exchange system should be further standardized, and the information included in the system should be further specified and augmented. International Health Terminology Standards (Systematized Nomenclature of Medicine Clinical Terms [SNOMED-CT]) should be introduced to standardize the different terminologies used for the same items in different data platforms, as well as the different ranges of reference values for test results. To provide EMRs with PGHD for medical institutions, the FHIR standards should also be applied. 
2) Plans for facilitating participation by private healthcare institutions and healthcare workers

In contrast to the international cases reviewed above, private hospitals play a large role in healthcare services in South Korea. Even if a PHR system is initially established with public institutions at the center, PHR services that are meaningful for patients may be difficult to provide without the participation of private healthcare institutions. Legal systems to facilitate participation by private healthcare institutions have not been sufficiently prepared, payment models and financial sources for providing incentives are uncertain, and the HIE project has not yet reached the settlement stage. Therefore, it is necessary to analyze international cases involving participation of healthcare workers and conduct in-depth discussions with stakeholders in South Korea.

3) National-level PHRs as patient-centered health management platform

The Australian MyHR is accessible only through its website, its website with apps, and the NHS App of the United Kingdom has opened the possibility of linking and integrating with apps developed by external healthcare information providers. In South Korea, the national level PHR, My HealthWay, has progressed and is expected to be built by 2022. It has to be established in a short time, 3 years, with a limited budget, and should therefore focus on the most fundamental purpose of PHRs. The system should enable patients to access their own healthcare information online and control access authorization. Interoperability standards should be applied to prepare channels through which medical and health management information can be transmitted or linked smoothly. The channels will serve as a foundation upon which the medical and healthcare industries can build various new and valuable services for patients. A study on the long-term impact of changes in the medical ecosystem according to the patient's access right to medical data based on national PHR services (My HealthWay) should also be planned and conducted.

\section{Conflict of Interest}

No potential conflict of interest relevant to this article was reported.

\section{Acknowledgments}

This research was supported by the Ministry of Health and Welfare, Republic of Korea.

\section{ORCID}

Jisan Lee (https://orcid.org/0000-0002-9039-7448)

Young-Taek Park (https://orcid.org/0000-0002-7574-4165)

Yu Rang Park (https://orcid.org/0000-0002-4210-2094)

Jae-Ho Lee (https://orcid.org/0000-0003-2619-1231)

\section{References}

1. Tang PC, Ash JS, Bates DW, Overhage JM, Sands DZ. Personal health records: definitions, benefits, and strategies for overcoming barriers to adoption. J Am Med Inform Assoc 2006;13(2):121-6.

2. Sun S, Zhou X, Denny JC, Rosenbloom TS, Xu H. Messaging to your doctors: understanding patient-provider communications via a portal system. Proceedings of the SIGCHI Conference on Human Factors in Computing Systems; 2013 Apr 27-May 2; Paris, France. p. 1739-48.

3. Heart T, Ben-Assuli O, Shabtai I. A review of PHR, EMR and EHR integration: a more personalized healthcare and public health policy. Health Policy Technol 2017; 6(1):20-5.

4. Choi BK, Park YT, Kwon LS, Kim YS. Analysis of platforms and functions of mobile-based personal health record systems. Healthc Inform Res 2020;26(4):311-20.

5. Kim YG, Jung K, Park YT, Shin D, Cho SY, Yoon D, et al. Rate of electronic health record adoption in South Korea: a nation-wide survey. Int J Med Inform 2017;101: 100-7.

6. Global Digital Health Partnership. Clinical engagement in digital health: an international overview of enablers and barriers [Internet]. New Delhi, India: Global Digital Health Partnership; 2019 [cited at 2021 Apr 20]. Available from: https://s3-ap-southeast-2.amazonaws.com/ ehq-production-australia/53772b23aabfdac950fe9e0e21 7592030439c3b2/documents/attachments/000/102/275/ original/GDHP_ClinConEngage_2.06.pdf.

7. Park Y, Yoon HJ. Understanding personal health record and facilitating its market. Healthc Inform Res 2020; 26(3):248-50.

8. Sabes-Figuera R, Maghiros I. European hospital survey: benchmarking deployment of e-Health services (20122013) [Internet]. Luxemburg: Publications Office of the European Union; 2013 [cited at 2021 Apr 20]. https:// publications.jrc.ec.europa.eu/repository/bitstream/ JRC85854/jrc85854.pdf.

9. Lupianez-Villanueva F, Folkvord F, Fauli C. Benchmarking deployment of eHealth among general practitio- 
ners. Luxemburg: Publications Office of the European Union; 2018.

10. Oderkirk J. Readiness of electronic health record systems to contribute to national health information and research. Paris, France: OECD Publishing; 2017.

11. Australian Digital Health Agency. View your record using an app [Internet]. Sydney, Australia: Australian Digital Health Agency; c2021 [cited at 2021 Apr 20]. Available from: https://www.myhealthrecord.gov.au/foryou-your-family/howtos/view-your-record-using-app.

12. Australian Digital Health Agency. My health record statistics [Internet]. Sydney, Australia: Australian Digital Health Agency; c2021 [cited at 2021 Apr 20]. Available from: https://www.myhealthrecord.gov.au/statistics.

13. Best J. The NHS App: opening the NHS's new digital "front door" to the private sector. BMJ 2019;367:16210.

14. NHS. Online version of the NHS Long term Plan [Internet]. London, UK: NHS; c2021 [cited at $2021 \mathrm{Apr}$ 20]. Available from: https://www.longtermplan.nhs.uk/ online-version/.

15. NHS. BETA - NHS digital, data and technology standards framework [Internet]. London, UK: NHS; 2021 [cited at 2021 Apr 20]. Available from: https://digital. nhs.uk/about-nhs-digital/our-work/nhs-digital-dataand-technology-standards/framework.

16. Government of Nova Scotia: MyHealthNS Services Winding Up [Internet]. Nova Scotia, Canada: Government of Nova Scotia; c2020 [cited 2021 Apr 23]. Available from: https://novascotia.ca/news/release/?id=20200214005.
17. Grudic J. 'At my breaking point': Halifax doctor pulls out of online health care tool [Internet]. Vancouver, Canada: Global News; 2017 [cited at 2021 Apr 20]. Available from: https:/globalnews.ca/news/3580435/atmy-breaking-point-halifax-doctor-pulls-out-of-onlinehealthcare-tool/.

18. OECD. Health in the 21st century: putting data to work for stronger health systems. Paris, France: OECD Publishing; 2019.

19. 1177 Vardguiden [Internet]. Stockholm, Sweden: 1177 Vardguiden; c2021 [cited at 2021 Apr 20]. Available from: https://www.1177.se.

20. Moll J, Rexhepi H, Cajander A, Grunloh C, Huvila I, Hagglund M, et al. Patients' experiences of accessing their electronic health records: national patient survey in Sweden. J Med Internet Res 2018;20(11):e278.

21. Armstrong S. Patient access to health records: striving for the Swedish ideal. BMJ 2017;357:j2069.

22. Hagglund M, DesRoches C, Petersen C, Scandurra I. Patients' access to health records. BMJ 2019;367:15725.

23. Vehko T, Ruotsalainen S, Hypponen H. E-health and ewelfare of Finland: check point 2018. Helsinki, Finland: National Institute for Health and Welfare (THL); 2019.

24. Nohr C, Parv L, Kink P, Cummings E, Almond H, Norgaard JR, et al. Nationwide citizen access to their health data: analysing and comparing experiences in Denmark, Estonia and Australia. BMC Health Serv Res 2017;17(1): 534. 